Chapman University

Chapman University Digital Commons

Psychology Faculty Articles and Research

Psychology

$11-14-2017$

\title{
Prenatal Maternal Mood Patterns Predict Child Temperament and Adolescent Mental Health
}

Laura M. Glynn

Chapman University, lglynn@chapman.edu

Mariann A. Howland

University of California, Irvine

Curt A. Sandman

University of California, Irvine

Elyssia P. Davis

University of California, Irvine

Michael Phelan

University of California, Irvine

See next page for additional authors

Follow this and additional works at: http://digitalcommons.chapman.edu/psychology_articles

\section{Recommended Citation}

Glynn, L. M., Howland, M. A., Sandman, C. A., Davis, E. P., Phelan, M., Baram, T. Z., \& Stern, H. S. Prenatal maternal mood patterns predict child temperament and adolescent mental health. Journal of Affective Disorders, 228: 83-90. doi: 10.1016/j.jad.2017.11.065

This Article is brought to you for free and open access by the Psychology at Chapman University Digital Commons. It has been accepted for inclusion in Psychology Faculty Articles and Research by an authorized administrator of Chapman University Digital Commons. For more information, please contactlaughtin@chapman.edu. 


\section{Prenatal Maternal Mood Patterns Predict Child Temperament and Adolescent Mental Health}

\section{Comments}

NOTICE: this is the author's version of a work that was accepted for publication in Journal of Affective Disorders. Changes resulting from the publishing process, such as peer review, editing, corrections, structural formatting, and other quality control mechanisms may not be reflected in this document. Changes may have been made to this work since it was submitted for publication. A definitive version was subsequently published in Journal of Affective Disorders, volume 228, in 2017. DOI:10.1016/j.jad.2017.11.065

The Creative Commons license below applies only to this version of the article.

\section{Creative Commons License}

\section{(c) (1) (8)}

This work is licensed under a Creative Commons Attribution-Noncommercial-No Derivative Works 4.0 License.

\section{Copyright}

Elsevier

\section{Authors}

Laura M. Glynn, Mariann A. Howland, Curt A. Sandman, Elyssia P. Davis, Michael Phelan, Tallie Z. Baram, and Hal S. Stern 


\section{Author's Accepted Manuscript}

Prenatal Maternal Mood Patterns Predict Child Temperament and Adolescent Mental Health

Laura M. Glynn, Mariann A. Howland, Curt A. Sandman, Elysia P. Davis, Michael Phelan, Tallie Z. Baram, Hal S. Stern

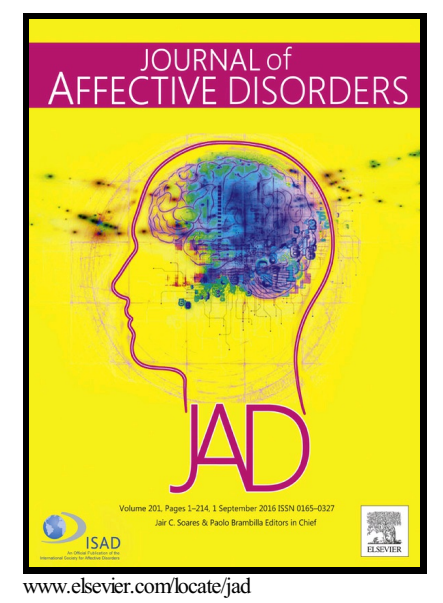

PII: S0165-0327(17)31125-4

DOI: $\quad$ https://doi.org/10.1016/j.jad.2017.11.065

Reference: JAD9379

To appear in: Journal of Affective Disorders

Received date: 3 June 2017

Revised date: 8 September 2017

Accepted date: 13 November 2017

Cite this article as: Laura M. Glynn, Mariann A. Howland, Curt A. Sandman, Elysia P. Davis, Michael Phelan, Tallie Z. Baram and Hal S. Stern, Prenatal Maternal Mood Patterns Predict Child Temperament and Adolescent Mental Health, Journal of Affective Disorders, https://doi.org/10.1016/j.jad.2017.11.065

This is a PDF file of an unedited manuscript that has been accepted for publication. As a service to our customers we are providing this early version of the manuscript. The manuscript will undergo copyediting, typesetting, and review of the resulting galley proof before it is published in its final citable form. Please note that during the production process errors may be discovered which could affect the content, and all legal disclaimers that apply to the journal pertain. 


\title{
Prenatal Maternal Mood Patterns Predict Child Temperament and
} Adolescent Mental Health

\author{
Laura M. Glynn ${ }^{1,2 *}$, Mariann A. Howland ${ }^{2}$, Curt A. Sandman ${ }^{2}$, Elysia P. Davis ${ }^{2,3}$, Michael Phelan ${ }^{4}$, Tallie Z. \\ Baram $^{5,6,7}$, Hal S. Stern ${ }^{4}$ \\ ${ }^{1}$ Department of Psychology, Chapman University, Orange, CA, USA \\ ${ }^{2}$ Department of Psychiatry and Human Behavior, University of California, Irvine, CA, USA \\ ${ }^{3}$ Department of Psychology, University of Denver, Denver, CO, USA \\ ${ }^{4}$ Department of Statistics, University of California, Irvine, CA, USA \\ ${ }^{5}$ Department of Anatomy/Neurobiology, University of California, Irvine, CA USA \\ ${ }^{6}$ Department of Pediatrics, University of California, Irvine, CA, USA \\ ${ }^{7}$ Department of Neurology, University of California, Irvine, CA, USA \\ ${ }^{*}$ Corresponding author at: Department of Psychology, Chapman University, Orange, CA, USA. \\ Iglynn@chapman.edu
}

\section{Abstract}

\section{Background}

This study quantifies the dynamics of maternal mood focusing on unpredictability, and to assess if greater unpredictability of prenatal maternal mood predicts child temperament and internalizing symptoms through early adolescence.

\section{Methods}

The association between prenatal mood predictability and child internalizing symptoms were assessed in two longitudinal cohorts ( $\mathrm{N}^{\prime} \mathrm{s}=227$ and 180). Maternal mood was assessed repeatedly during pregnancy as early as 15 weeks' gestation. Predictability of maternal mood was calculated by applying Shannon's entropy to the distribution of responses on mood questionnaires. Maternal reports of child negative affectivity (a predictor of later internalizing) were collected at 6, 12, 24 months and 7 years of age. Child self-reports of anxiety symptoms were collected at 10 years and reports of depression symptoms at 13 years. 


\section{Results}

Fetal exposure to more elevated maternal mood entropy predicted higher levels of child negative affectivity at 12 months $(r=.36 ; p<01), 24$ months $(r=.31 ; p<01)$ and 7 years $(r=.32 ; p<01)$ of age. In addition, children exposed to higher prenatal maternal mood entropy, reported higher levels of anxiety symptoms at 10 years $(r=.24 ; p<01)$ and elevated depressive symptoms at 13 years $(r=.29 ; p$ $<.01)$. These associations persisted after adjusting for maternal pre and postnatal mood valence (e.g. depression levels) and for other relevant demographic characteristics.

\section{Conclusions}

Our findings provide strong support for the notion that patterns of maternal mood influence the developing brain. More specifically, they suggest that prenatal maternal mood predictability may be a critical predictor of developmental mental health trajectories and should be considered when assessing early life influences on lifespan mental health.

\section{Keywords}

Prenatal, Postpartum, Pregnancy, Depression, Anxiety, Temperament, Child Development, Entropy, Internalizing Disorders, Adolescence, Emotion Regulation

\section{Introduction}

Few families in the United States escape the burden imposed by mental illness. The lifetime prevalence among adolescents in the US is estimated to be $46.3 \%$ for any mental health disorder and 21.4\% for severe disorders (Merikangas et al., 2010). The National Comorbidity Survey Replication study estimated that exposure to early-life adversity may account for 32.4 percent of psychiatric disorders (Green et al., 2010). Prenatal and early life stress and trauma exposures have been linked to a broad range of mental health conditions including schizophrenia, depression, anxiety, and posttraumatic stress disorder (Gilbert et al., 2009; Heim and Nemeroff, 2001; Khashan et al., 2008; Kingsbury et al., 2016). Evidence from human studies (Qiu et al., 2015; Slopen et al., 2012; Woon and Hedges, 2008) and from animal models (Avishai-Eliner et al., 2002; Chen and Baram, 2016; Gunnar et al., 2015; Spinelli et al., 2009) further suggests that exposure to prenatal and early-life adversity may be causally related to brain changes underlying the risk for psychopathology. 
Given the accumulating evidence relating prenatal maternal psychological distress to risk for mental health disorders and their underlying neural mechanisms (Babenko et al., 2015; Buss et al., 2010; Huizink et al., 2002; Khashan et al., 2008; Lebel et al., 2015), an important next step is the identification of specific components of maternal signals that shape the developing brain. Previous work indicates that patterns of maternal sensory input, particularly fragmented or unpredictable signals, influence the maturation of systems governing emotional regulation in the offspring's developing brain (Baram et al., 2012; Davis et al., in press). For example, rodents that are exposed to unpredictable patterns of maternal-derived sensory input during postnatal life, exhibit diminished cognitive function and increased anhedonia beginning in adolescence (Brunson et al., 2005; Ivy et al., 2010; Molet et al., 2016). Importantly, these effects are independent of the quantity of these maternal behaviors, underscoring the importance of patterns of unpredictability in shaping the immature brain.

Analysis of intraindividual patterns in behaviors and attitudes is rooted in personality psychology (c.f. Fiske and Rice, 1955; Mischel and Shoda, 1995) and has been most commonly characterized as either intraindividual variability in item scores on a questionnaire or intraindividual fluctuations across situations and time (Eid and Diener, 1999; Penner et al., 1994). Further, for the past 50 years, emotion theory has recognized that mood patterns, independent of level, are central components of affective experience in their own right (Larsen and Diener, 1987; Wessman and Ricks, 1966). There exist a range of techniques for studying emotion dynamics which include examination of patterns over time (e.g. weeks or months) and dynamics at a single point in time, capturing a snapshot of emotional experience (Kuppens and Verduyn, 2015). Intraindividual variability in mood and affect has implications for understanding both clinical and non-clinical emotional states and traits. For example, more extreme variability in mood has been linked to higher levels of affect intensity (Larsen and Diener, 1987), more self-complexity (Campbell et al., 1991), lower self-esteem (Kuppens et al., 2007) and to a range of personality traits including neuroticism, extraversion and sensation seeking (Hepburn and Eysenck, 1989; Larsen and Kasimatis, 1990). Increased mood variability across hours or days, also has been linked to risk for bipolar disorders (Bonsall et al., 2012; Depue et al., 1981), clinical and sub-clinical depression (Kuppens et al., 2007; Thompson et al., 2011), and anxiety disorders (Bowen et al., 2006). These theoretical perspectives and the empirical findings highlighting the link between individual differences in mood variability and risk for psychopathology are consistent with a 
broader growing literature that identifies deficits in emotion regulation as a transdiagnostic factor in mental health and in mood disorders in particular (Aldao et al., 2010; Fernandez et al., 2016; Kring and Sloan, 2010).

We examine here whether unpredictability of prenatal maternal mood might influence the developing fetus. We characterize unpredictability in mood using a measure of normalized entropy. Specifically, we examine whether maternal prenatal mood entropy predicts child temperament and internalizing symptoms over and above the well-established relations with levels of maternal mood in two independent, prospective, longitudinal cohorts of women and their children ( $\mathrm{Ns}=227$ and 180) who were followed beginning at 15 weeks' gestation through early adolescence.

\section{Materials and Methods}

\section{Overview of Data Collection}

Participants were recruited from affiliated clinics from one of two large university medical centers in Southern California. Recruitment criteria included: 1) singleton pregnancy 2) over the age of 18,3 ) English speaking 4) non-smoking, and 5) absence of any condition that could dysregulate neuroendocrine function. Participants in both cohorts were recruited during the first trimester of pregnancy and participated in four to five prenatal study visits (See Figure 1). In addition, the motherchild pairs participated in postnatal visits that began as early as 6 months through 13 years of age. Cohort 1 consisted of 227 mother-child pairs and Cohort 2 of 180 pairs. The number and distribution of both pre- and postnatal visits differed by cohort and can be seen in Figure 1. Characteristics of motherchild pairs are presented in Table 1. At each of the prenatal study visits mothers reported on demographics and mood through questionnaires and structured interviews. At each of the postnatal visits, the mothers completed assessments of developmentally-appropriate predictors of risk for internalizing disorders and also reported on their own mood. Children reported on their own anxiety symptoms at age 10 and on their depressive symptoms at age 13. Research was approved by the responsible institutional review board and all mothers provided written informed consent after the procedures had been fully explained. In addition, children provided assent at the study visits at 7, 10 and 13 years of age. 


\section{Characterization of Mood Unpredictability}

\section{Parameters Assessed}

Depressive Symptoms Maternal depressive symptoms were characterized using the nine-item form of the Center for Epidemiologic Studies Depression Scale (Santor and Coyne, 1997) during the prenatal visits and at all postnatal visits except for 7-years (see Figure 1). Responses to each of the nine items in this measure were recorded on a 4-point Likert scale, with a range of 0 to 3 . The final score could span from 0 to 27 , with a higher score indicating greater impairment. This measure has been extensively used, and published studies demonstrate good internal consistency and validity in both pregnant women and in the general population (Marcus et al., 2003; Santor and Coyne, 1997). At the 7-year assessment maternal depressive symptoms were assessed with the Beck Depression Inventory (BDI; Beck et al., 1961). The BDI is a 21-item instrument that exhibits high internal consistency (alphas $>$.81) in both psychiatric and non-psychiatric populations (Beck et al., 1988). In addition, it possesses significant validity in detecting the differences between depressed and non-depressed individuals (Richter et al., 1998).

State Anxiety State anxiety was measured with the 10-item state anxiety subscale of the StateTrait Personality Inventory (Spielberger, 1979). Various anxiety-related adjectives were rated on a 4point scale. This brief measure has demonstrated good psychometric properties when used in pregnant and non-pregnant populations (Glynn et al., 2008; Spielberger, 1979).

Pregnancy Specific Anxiety A 10-item scale was used to address a woman's feelings about her health during pregnancy, the health of her baby, and her feelings about labor and delivery (Rini et al., 1999). Answers are given on a 4-point scale and included items such as: "I am fearful regarding the health of my baby," "I am concerned or worried about developing medical problems during my pregnancy." This measure exhibits good internal validity (Glynn et al., 2008; Rini et al., 1999) and is predictive of birth and child development outcomes (c.f.Buss et al., 2010; Dunkel Schetter and Glynn, 2011)).

Perceived Stress The Perceived Stress Scale (Cohen et al., 1983) was used to assess the extent to which situations in one's life are appraised as stressful. This instrument includes questions regarding 
how often women felt they were able to successfully manage day-to-day problems and hassles and how often they felt nervous or stressed. Responses are given on a 5-point Likert scale. The scale is predictive of a wide range of physical and mental health outcomes (Cohen et al., 1993; Hewitt et al., 1992) and demonstrates good reliability (Cohen et al., 1983).

\section{Calculation of Mood Predictability}

To characterize predictability or consistency of mood, we calculated an entropy score by applying Shannon's entropy to the distribution of responses on the four mood questionnaires individually at each visit (Cover and Thomas, 2006). Shannon's entropy is associated with the concept of information and the efficiency with which messages can be sent along binary communication channels. The formula is given here:

$$
\mathrm{ENT}=-\sum_{e \in E} p_{e} \log _{2}\left(p_{e}\right)
$$

In this formula, E denotes the range of possible responses for items on a mood scale (say 0 to 3 on the PSS) and $p_{e}$ represents the proportion of responses in each category. This application involves a quantification of unpredictability of the item-by-item responses to assessments of mood states. The responses at a single assessment are tabulated over the items within each scale into probability distributions based on the relative frequency of each response choice, and these distributions represent empirical estimates of the propensity of a study subject to respond across items in a consistent way. In this sense, mood entropy quantifies the degree of predictability of the item-specific response. A participant who generally reports never worried or always secure on the STAI, for example, would be considered very predictable and thus have a very low entropy score, whereas a woman who completes the STAl items entirely at random would have a very high entropy score. Table 2 presents an example of the responses of a single participant to the STAI items and how these are used to compute the entropy for that individual on that scale. The entropy measure for a scale ranges from zero (perfectly predictable) to a maximum value that depends on the number of points on the scale. To facilitate application of the approach across the different mood questionnaires we normalized the entropy score by expressing it as a percentage of the maximum value. Thus normalized entropies range from 0 to 100 . 


\section{Test of Discriminant Validity}

It is possible that rather than reflecting something about mood regulation, that the measure of entropy reflects instead a general tendency to answer questionnaire items in an unpredictable or inconsistent manner. To evaluate this alternate explanation, we calculated an entropy score from a scale assessing physical activity during the prenatal period. This 10-item Likert scale asks participants to rate their average time spent on various types of physical activities including: "hours per day sitting" and "hours per day walking." Answers are given on a 12-point scale that ranges from 1 (one or less hours) to 12 (12 or more hours). This scale shows similar psychometric properties to the mood indices.

\section{Test of Convergent Validity}

We additionally tested the convergent validity of our mood entropy measure by examining its association with affective instability, a time-based, momentary measure of mood variability. In a third ongoing, prospective, longitudinal study of pregnant women $(n=151)$, mood entropy scores were derived exactly as described above from questionnaire data obtained at a laboratory visit at 15 weeks' gestation. In addition, an experience sampling (Csikszentmihalyi and Larson, 1987) or ecological momentary assessment (EMA; Stone and Shiffman, 1994) protocol was then completed within two weeks of the laboratory visit. These momentary mood assessments were delivered eight times a day for three consecutive days on a semi-random schedule via smart phone application (mEMA, Ilumivu). Daily mood variability scores were calculated from EMA measures parallel to those questionnaires comprising the mood entropy index (CESD-VAS-VS:Moullec et al., 2011; PSS-4:Cohen and Williamson, 1988; anxious mood subscale of POMS-15:Cranford et al., 2006) using the standard root mean square successive difference (RMSSD; see Ebner-Priemer et al., 2009; Jahng et al., 2008; Solhan et al., 2009). RMSSD scores for each measure for each day were averaged. For ease of interpretation, a single RMSSD index was calculated by averaging standardized RMSSD scores across the three measures. RMSSD index scores did not vary as a function of compliance (total number of assessments completed; $r=-.04, \mathrm{~ns})$. 


\section{Characterization of Risk for Internalizing Disorders}

\section{Negative Affectivity}

Child negative affectivity was assessed at 6 and 12 months with the Infant Behavior Questionnaire (IBQ; (Gartstein and Rothbart, 2003), at 2 years with the Early Childhood Behavior Questionnaire (ECBQ; (Putnam et al., 2006) and at 7 years with the Children's Behavior Questionnaire (CBQ; Rothbart et al., 2001). These scales contain developmentally appropriate, maternal report measures of Negative Affectivity, a temperament dimension which predicts later internalizing symptoms (Gulley et al., 2016). These instruments were developed specifically to reduce the possibility of maternal reporting bias by asking about specific behaviors in defined situations, rather than asking for judgments about child temperament or behaviors. Responses on these scales range from 1 (never) to 7 (always). These measures exhibit good internal reliability and validity (Goldsmith and Campos, 1990; Worobey and Blajda, 1989).

\section{Child Report of Anxiety Symptoms}

Children completed the trait anxiety (T-Anxiety) scale from the State-Trait Anxiety Inventory for Children (STAIC; Spielberger et al., 1973) as part of a structured interview. This 20-item scale is designed to assess anxiety-proneness. The interviewer read 20 statements (e.g., "I worry about making mistakes," "I worry about things that may happen"). After each statement, the child was asked to decide whether the statement was "hardly ever," "sometimes," or "often" true for him/her. These responses are assigned values of 1,2, and 3, respectively, allowing sum scores to range from 20 to 60. The STAIC has good test-retest reliability and internal consistency (Spielberger et al., 1973). It also exhibits good predictive (Seligman et al., 2004) and concurrent validity, with STAIC trait anxiety scores correlating at $r=.75$ and .63 with scores on the Children's Manifest Anxiety Scale (Castaneda et al., 1956) and General Anxiety Scale for Children (Sarason et al., 1960), respectively. 


\section{Adolescent Report of Depressive Symptoms}

The 12-item short self-report version of the Children's Depression Inventory (CDI 2; Kovacs, 2011) was used to assess adolescent depressive symptoms. The interviewer read 12 sets of three statements, and the child was asked to indicate which of the statements best described him or her in the past two weeks (e.g., "I am sad once in a while," "I am sad many times," or "I am sad all the time," scored 0, 1, and 2 respectively). Scores on the CDI can range from 0 to 24 . The CDI has been validated and used extensively in previous research involving children and adolescents (Kovacs, 2011; Stockings et al., 2015; Timbremont et al., 2004)

\section{Data Analysis}

When child age at assessment overlapped (See Figure 1), data from the two cohorts were combined in analyses. Bivariate correlations were used to assess relations between mood entropy and child outcomes. Partial correlations were then used to assess plausible third variable explanations (See Table S1). Potential covariates in these analyses included: socioeconomic status (a composite was created by standardizing maternal education level and household income and then averaging the two), race/ethnicity (self-identified), maternal age, cohabitation with father during pregnancy, child sex, gestational age at birth, birth order, and child age at assessment. The following variables exhibited an association $p<.05$ with both the predictor and outcomes and so were included as covariates in all analyses: maternal age, socioeconomic status, cohabitation, gestational age at birth and child age at assessment. In addition, because mood entropy was modestly correlated with mood levels (range .26 to .69), and because pre and postnatal maternal mood states have been demonstrated to influence temperament and internalizing symptoms, we included both pre and postnatal mood levels in the models. Last, linear regression models tested whether any prenatal mood entropy effects that were detected could be accounted for by postnatal maternal mood entropy. In these models prenatal mood entropy and postnatal mood entropy at the time point of the child assessment both were entered simultaneously into the models as predictors. 
Our planned analyses include bivariate correlations of entropy with child negative affectivity and internalizing symptoms and partial correlations adjusting for plausible confounders. Thus, we test twelve correlations. We use the false discovery rate approach (Benjamini and Hochberg, 1995; Benjamini and Yekutieli, 2001) to adjust for the multiple comparisons.

Because of the well-established relations between child temperament and risk for psychopathology, as a secondary aim, we examined whether child negative affectivity mediated any associations between prenatal mood entropy and later child anxiety and depressive symptoms. Specifically, four separate mediation models were utilized to evaluate potential indirect effects of maternal prenatal mood entropy (independent variable) as a predictor of child anxiety and adolescent depressive symptoms (dependent variables) through infant and child negative affectivity (mediators). Models were evaluated with the bootstrapping procedure described in Preacher \& Hayes (2004), using 5000 bootstrap samples and a 95\% bias-corrected confidence interval.

\section{Results}

\section{Mood Entropy}

Mood entropy was stable across gestation for both cohorts with no reliable patterns of differences based on gestational time point for any of the four measures. The means across the four measures ranged from 48.5 to 59.4 and the variances of the entropy scores also were similar for each of the four mood measures (sd's ranged from 17.6 to 24.9). For each of the four scales, average correlations of mood entropy across gestation ranged from .44 to .54. Because of these findings, a single mood entropy index was created by averaging mood entropy scores within each scale and then averaging these gestational averages (correlations among these averages ranged from .34 to .53). A similar strategy was employed to create a single mood level composite for the prenatal period and the mood measures were similarly standardized and averaged at each of the postnatal assessments.

\section{Test of Discriminant Validity: Mood Entropy or Entropy in Response Style?}

The correlation between mood entropy and entropy calculated from the physical activity questionnaire was .08 (ns). However, unlike mood entropy, entropy in responses to the physical activity 
questionnaire was not predictive of maternal reports of child negative affectivity ( $r$ 's ranged from .01 to .10 , all ns) nor of child self-reports of anxiety and depressive symptoms ( $r^{\prime} s=-.03$ and .07 respectively, both ns).Prenatal Maternal Mood Entropy and Maternal Report of Negative Affectivity

Higher maternal prenatal mood entropy was predictive of increased child negative affectivity at 6 ( $r=$ $.23, p<.01)$ and 12-months of age $(r=.36, p<.01$; See Figure 2$)$. These positive associations also were observed at 24 months $(r=.31, p<.01)$ and at 7 years of age $(r=.32, p<.01$; See Figure 2$)$. In addition, the relations at 12 months (partial $r=.18$; $p<05$ ), 24 months (partial $r=.19 ; p<05$ ) and 7 years (partial $r=.14 ; \mathrm{p}<05$ ) persisted after adjustment for gestational age at birth, child age at assessment, socioeconomic status, cohabitation with the child's father, maternal age, prenatal mood level and concurrent postnatal mood level. The association between mood entropy and negative affectivity at 6months of age, did not survive adjustment for covariates (partial $r=-.06 ; p=.41$ ).

\section{Prenatal Mood Entropy and Child Report of Anxiety and Adolescent Report of Depressive Symptoms}

Higher prenatal mood entropy was associated with increased child report of anxiety symptoms at age $10(r=.24 ; p<01$; See Figure 3a) and with adolescent reports of depressive symptoms at age 13 ( $r=$ $.29 ; p<.01$; See Figure 3b). Similar to the relations between mood entropy and maternal reports of fearful temperament, the effects persisted after adjusting for gestational age at birth, child age at assessment, socioeconomic status, cohabitation with the child's father, maternal age, prenatal mood level and concurrent postnatal mood (partial $r^{\prime} s=.24, p<01$ and $.17, p<.05$, respectively).

\section{Multiple Comparisons}

The six bivariate correlations of entropy with negative affectivity and internalizing symptoms are all significant with $p<.01$. Five of the six partial correlations tested are significant with $p<.05$. A false discovery rate with $5 \%$ false discoveries identifies all 11 of the significant correlations as discoveries.

\section{Test of Convergent Validity}

Prenatal mood entropy scores were positively associated with RMSSD affective instability scores, $r=$ $.42, p<.001$. In other words, women with higher levels of mood entropy exhibited higher levels of affective instability across three days in the course of their daily lives. 


\section{Test of the Unique Contributions of Prenatal Mood Entropy}

Table 3 contains summaries of the regression models in which both pre and postnatal mood entropy were modeled together. At each time point (12 and 24 months, 7 years), both pre and postnatal maternal mood entropy were independently and positively associated with maternal report of child negative affectivity. For child report of state anxiety, pre and postnatal entropy each dropped to the trend level of statistical significance. Last, for adolescent report of depressive symptoms, both pre and postnatal mood entropy remained statistically significant predictors in the model.

\section{Testing Relations between Temperament and Internalizing Symptoms}

As expected, infant and child negative affectivity was positively associated with child anxiety symptoms (See Table S1). However, models testing mediation failed to reveal any significant indirect effects of prenatal mood entropy on child anxiety and adolescent depressive symptoms through infant or child negative affectivity (see Table S2 for details).

\section{Discussion}

These results identify mood entropy as a novel marker of prenatal maternal mood dysregulation that exhibits persisting associations with risk for internalizing symptoms in offspring. Specifically, we demonstrate that mood entropy predicts maternal reports of negative affectivity in infancy and childhood as well as child and adolescent self-reports of anxiety and depressive symptoms. Importantly, the effects of prenatal mood entropy were independent of pre and postnatal maternal mood levels, other well-established contributors to child mental health (Monk et al., 2012; O'Connor et al., 2003; Pearson et al., 2013; Sandman et al., 2015) and these effects appear to be independent of postnatal mood entropy. There are three critical components of the methodology that increase our confidence in the importance of this new indicator of mood dysregulation. First, the results cannot be attributed to maternal characteristics associated with questionnaire response style. Identical entropy values calculated from a prenatal questionnaire assessing physical activity, which has similar psychometric properties to the mood questionnaires were not predictive of child internalizing symptoms. Second, mood entropy was positively associated with mood variability measured across 
days in the field with ecological momentary assessment techniques. Third, the results reflect not only maternal report of fearful temperament, but child self-report of anxiety and depressive symptoms as well, which further suggests that this is not simply an artifact of maternal reporting style or bias.

Because negative affectivity is a temperament dimension that represents a well-established risk factor for internalizing problems (Dougherty et al., 2010; Dar and Iqbal, 2015; Markon et al., 2005; Sayal et al., 2014; Tortella-Feliu et al., 2010), as a secondary aim, we tested whether the association between mood entropy and child anxiety and adolescent depressive symptoms might be mediated partially or fully through temperament in infancy and childhood. Here we replicate previously established relations between temperament and psychopathology risk - negative affectivity in infancy and childhood did predict later internalizing symptoms. However, the results of our analyses did not support the supposition that temperament plays a role in the causal pathway linking mood entropy to child psychopathology risk. It may be the case that these null findings are veridical. However, it also is possible that we did not detect relations because these children represent relatively low-risk, typically developing individuals or because these relations would not be revealed without consideration of moderated-mediation (Kiel and Buss, 2011; Dunkel Schetter and Glynn, 2011). Temperamentpsychopathology relations are often not detected without careful consideration of the moderating factors associated with contextual risk (Degnan et al., 2010; Hentges et al., 2015; e.g. peer groups, Frenkel et al., 2015; father absence, Boyce et al., 2006); stress exposures, Gulley et al., 2016), the examination of which extends beyond the scope of this study.

Although it is clear that maternal mood entropy is a consistent predictor of child mental health risk, it is less clear what this index reflects about women's experience of mood or emotion regulation. The two primary possibilities related to emotional experience that could account for variation in mood entropy are lability of emotions and alexithymia, both of which are plausible and not mutually exclusive. Women who exhibit high mood entropy profiles may experience wide variations in their emotional experiences, it also possible that high mood entropy is indicative of a lack of emotional clarity or an inability to properly differentiate emotions (Boden et al., 2013). Our data linking mood entropy to mood lability measured over days with EMA methods support the argument that mood entropy does reflect in part individual differences in mood variability. Both mood variability and 
alexithymia are predictive of clinical and subclinical psychopathology (Depue et al., 1981; Frewen et al., 2008; Kim et al., 2016; Thompson et al., 2011) and future research will have to determine further, the precise nature of the emotional dysregulation associated with mood entropy.

At this time, the mechanism underlying the association between prenatal maternal mood entropy and child internalizing remains unknown. Identification of such a mechanism represents a similar challenge to that currently faced by the literature documenting associations with levels of prenatal maternal distress (e.g. how does prenatal maternal depression, stress or anxiety influence the developing fetus). However, advances in studies examining the mechanisms underlying maternal prenatal distress levels and child outcomes may serve as an initial roadmap for domains to consider that may be relevant to mood entropy and these include: neural, endocrine, immune, epigenetic and vascular pathways (Christian, 2014; Hilmert et al., 2014; O'Donnell et al., 2009; Shea et al., 2008). We are aware of only one study to date that has examined the physiological signature associated with intraindividual mood variability. Koval et al. (2013) showed that higher levels of affective instability were predictive of lower heart rate variability in a sample of male and female undergraduates. This is notable because individual differences in vagally-mediated heart rate variability are associated with emotion regulation and are predictive of cardiac and psychological health outside of the perinatal period (Thayer et al., 2012). Further, a few studies have shown that reduced maternal prenatal heart rate variability is associated with increased maternal depressive symptoms (Rouleau et al., 2016; Shea et al., 2008) and experimental manipulation of maternal respiratory sinus arrhythmia results in alterations in maternal-fetal heart rate synchronization (Van Leeuwen et al., 2009). Clearly, these findings point to the need to determine whether mood entropy is associated with maternal heart rate variability or other potential biological mechanisms in the context of pregnancy.

The strengths of this study reside in the examination of the associations between prenatal maternal mood entropy and risk for child internalizing prospectively into adolescence in two prospective cohorts. Our confidence in the findings are greatly increased by the fact that we observe these associations with both measures of maternal report of child temperament as well as with child reports of their own anxiety and depressive symptoms. Further, careful characterization of mood levels and inclusion of these in our statistical models support the role of mood entropy as a novel predictor 
of child internalizing symptoms, which is independent of mood level or affective valence. A limitation of the entropy measure is that it reflects unpredictability during a very short period of time while the mother completed the relevant questionnaire, rather than unpredictability on a time scale that might be associated with fetal (and brain) development. This limitation is mitigated by the convergent validity results in the new cohort that show an association of the entropy measure with the RMSSD, which is based on affective instability measured over a period of days. A second weakness lies in the fact that this study is necessarily correlational, relying on naturally occurring variations in mood entropy rather than those that are experimentally manipulated. However, our results in humans are consistent with findings from experimental animal models, which demonstrate that exposure to entropy in maternal signals early in development exerts lasting influences on offspring brain and behavior (Brunson et al., 2005; Ivy et al., 2008; Molet et al., 2016).

Existing empirical research indicates that levels of prenatal maternal psychological distress are associated with a range of physical and mental health outcomes. However, interventions to reduce symptoms of anxiety and depression and reduce stress levels during pregnancy have met with only limited success (Fontein-Kuipers et al., 2014). Further, therapeutic strategies focused on increasing clarity and acceptance of emotions seem to be solid targets for positive change (Gratz and Gunderson, 2006; Reinares et al., 2014). Mindfulness-based intervention or interventions targeting alexithymia and emotion regulation are beginning to prove fruitful in treating a range of disorders outside the perinatal period (Kuyken et al., 2016; Spijkerman et al., 2016). It is possible that mood entropy may represent a new target for intervention during the perinatal period, with the potential to augment treatments focused on mood levels or valence. Mental health conditions are likely the downstream consequences of alterations to brain circuits, cognitions and behavior occurring much earlier in life. This new evidence suggests that maternal mood entropy may be a critical predictor of these developmental mental health trajectories and should be considered when assessing early life influences on lifespan mental health. 
All authors have seen and approved this manuscript. We confirm that the article is our original work, hasn't received prior publication and isn't under consideration for publication elsewhere.

Contributors

All authors contributed to study design and conceptualization. LG, CS and ED were responsible for data collection. LG, MH, HS and MP participated in analyses. LG drafted the manuscript. All authors provided critical editorial feedback.

Role of Funding Source

This research was supported by grants from the National Institutes of Health (HD-28413, HD-40967, HD-51852, NS-41298 and MH-96889). The authors have no conflicts of interest to disclose. These funding sources had no involvement in study design, data collection, analyses or the decision to submit the article.

\section{Acknowledgements}

The authors thank the families who participated in these projects. We also thank the dedicated staff at the Early Human and Lifespan Development Program and the Women and Children's Health and WellBeing project. This research was supported by grants from the National Institutes of Health (HD-28413, HD-40967, HD-51852, NS-41298 and MH-96889).

\section{Conflicts of Interest}

The authors have no conflicts of interest to disclose.

\section{References}

Aldao, A., Nolen-Hoeksema, S., Schweizer, S., 2010. Emotion-regulation strategies across psychopathology: A meta-analytic review. Clin Psychol Review 30, 217-237.

Avishai-Eliner, S., Brunson, K.L., Sandman, C.A., Baram, T.Z., 2002. Stressed-out, or in (utero)? Trends Neurosci $25,518-524$.

Babenko, O., Kovalchuk, I., Metz, G.A., 2015. Stress-induced perinatal and transgenerational epigenetic programming of brain development and mental health. Neurosci Biobehav Rev 48, 70-91. 
Baram, T.Z., Davis, E.P., Obenaus, A., Sandman, C.A., Small, S.L., Solodkin, A., Stern, H., 2012. Fragmentation and unpredictability of early-life experience in mental disorders. Am J Psychiatry 169, 907-915.

Beck, A.T., Steer, R.A., Garbin, M.A., 1988. Psychometric properties of the Beck Depression Inventory: Twentyfive years of evaluation. Clin Psychol Rev 8, 77-100.

Beck, A.T., Ward, C.H., Mendelson, M., Mock, J., Erbaugh, J., 1961. An inventory for measuring depression. Arch Gen Psychiatry 4, 561-571.

Benjamini, Y., Hochberg, Y., 1995. Controlling the false discovery rate: a practical and powerful apprach to multiple testing. J R Stat Soc Seri Series B 57, 289-300.

Benjamini, Y., Yekutieli, D., 2001. The control of the false discovery rate in multiple testing under dependence. Ann Stat 29, 1165-1188.

Boden, M.T., Thompson, R.J., Dizen, M., Berenbaum, H., Baker, J.P., 2013. Are emotional clarity and emotion differentiation related? Cogn Emot 27, 961-978.

Bonsall, M.B., Wallace-Hadrill, S.M., Geddes, J.R., Goodwin, G.M., Holmes, E.A., 2012. Nonlinear time-series approaches in characterizing mood stability and mood instability in bipolar disorder. Proc Biol Sci 279, 916-924.

Bowen, R., Baetz, M., Hawkes, J., Bowen, A., 2006. Mood variability in anxiety disorders. J Affect Disord 91, 165170.

Boyce, W.T., Essex, M.J., Alkon, A., Goldsmith, H.H., Kraemer, H.C., Kupfer, D.J., 2006. Early father involvement moderates biobehavioral susceptibility to mental health problems in middle childhood. J Am Acad Child Adolesc Psychiatry 45, 1510-1520.

Brunson, K.L., Kramar, E., Lin, B., Chen, Y., Colgin, L.L., Yanagihara, T.K., Lynch, G., Baram, T.Z., 2005. Mechanisms of late-onset cognitive decline after early-life stress. J Neurosci 25, 9328-9338.

Buss, C., Davis, E.P., Muftuler, L.T., Head, K., Sandman, C.A., 2010. High pregnancy anxiety during mid-gestation is associated with decreased gray matter density in 6-9-year-old children. Psychoneuroendocrinol 35, 141-153.

Campbell, J.D., Chew, B., Scratchley, L.S., 1991. Cognitive and emotional reactions to daily events: the effects of self-esteem and self-complexity. J Pers 59, 473-505.

Castaneda, A., McCandless, B.R., Palermo, D.S., 1956. The children's form of the manifest anxiety scale. Child Dev 27.

Chen, Y., Baram, T.Z., 2016. Toward Understanding How Early-Life Stress Reprograms Cognitive and Emotional Brain Networks. Neuropsychopharmacology 41, 197-206.

Christian, L.M., 2014. Effects of stress and depression on inflammatory immune parameters in pregnancy. Am J Obstet Gynecol 211, 275-277.

Cohen, S., Kamarck, T., Mermelstein, R., 1983. A global measure of perceived stress. J Health Soc Behav 24, 385396. 
Cohen, S., Tyrrell, D.A., Smith, A.P., 1993. Negative life events, perceived stress, negative affect, and susceptibility to the common cold. J Pers Soc Psychol 64, 131-140.

Cohen, S., Williamson, G.M., 1988. Perceived stress in a probability sample of the United States., In: Spacapan, S., Oskamp, S. (Eds.), The social psychology of health. Sage, Newbury Park, CA.

Cover, T.M., Thomas, J.A., 2006. Elements of Information Theory, 2nd ed. John Wiley and Sons, New York. Cranford, J.A., Shrout, P.E., lida, M., Rafaeli, E., Yip, T., Bolger, N., 2006. A procedure for evaluating sensitivity to within-person change: can mood measures in diary studies detect change reliably? Pers Soc Psychol Bull 32, 917929.

Csikszentmihalyi, M., Larson, R., 1987. Validity and reliability of the Experience-Sampling Method. J Nerv Ment Dis $175,526-536$.

Davis, E.P., Stout, S.A., Molet, J., Vegetabile, B., Glynn, L.M., Sandman, C.A., Hein, K., Stern, H., Baram, T.Z., in press. Early life exposure to unpredictable maternal sensory signals influences cognitive development: $A$ crossspecies approach. Proc Natl Acad Sci USA.

Degnan, K.A., Almas, A.N., Fox, N.A., 2010. Temperament and the environment in the etiology of childhood anxiety. J Child Psychol Psychiatry 51, 497-517.

Depue, R.A., Slater, J.F., Wolfstetter-Kausch, H., Klein, D., Goplerud, E., Farr, D., 1981. A behavioral paradigm for identifying persons at risk for bipolar depressive disorder: a conceptual framework and five validation studies. J Abnorm Psychol 90, 381-437.

Dougherty, L., Klein, D.N., Durbin, C., Hayden, E., Olino, T.M., 2010. Temperamental positive and negative emotionality and children's depressive symptoms: A longitudinal prospective study from age three to age ten. J Soc Clin Psychol 29, 462-488.

Dunkel Schetter, C., Glynn, L.M., 2011. Stress in pregnancy: Empirical evidence and theoretical issues to guide interdisciplinary research, In: Contrada, R., Baum, A. (Eds.), The Handbook of Stress Science: Biology, Psychology and Health. Springer Publishing Company, New York, pp. 321-343.

Ebner-Priemer, U.W., Eid, M., Kleindienst, N., Stabenow, S., Trull, T.J., 2009. Analytic strategies for understanding affective (in)stability and other dynamic processes in psychopathology. J Abnorm Psychol 118, 195-202.

Eid, M., Diener, E., 1999. Intraindividual variability in affect: reliability, validity and personality correlates. J Pers Soc Psychol 76, 662-676.

Fernandez, K.C., Jazaieri, H., Gross, J.J., 2016. Emotion Regulation: A Transdiagnostic Perspective on a New RDoC Domain. Cognit Ther Res 40, 426-440.

Fiske, D.W., Rice, L., 1955. Intra-individual response variability. Psychol Bull 52, 217-250.

Fontein-Kuipers, Y.J., Nieuwenhuijze, M.J., Ausems, M., Bude, L., de Vries, R., 2014. Antenatal interventions to reduce maternal distress: a systematic review and meta-analysis of randomised trials. BJOG 121, 389-397. 
Frenkel, T.I., Fox, N.A., Pine, D.S., Walker, O.L., Degnan, K.A., Chronis-Tuscano, A., 2015. Early childhood behavioral inhibition, adult psychopathology and the buffering effects of adolescent social networks: a twentyyear prospective study. J Child Psychol Psychiatry 56, 1065-1073.

Frewen, P.A., Dozois, D.J., Neufeld, R.W., Lanius, R.A., 2008. Meta-analysis of alexithymia in posttraumatic stress disorder. J Trauma Stress 21, 243-246.

Gartstein, M.A., Rothbart, M.K., 2003. Studying infant temperament via the Revised Infant Behavior Questionnaire. Infant Behav Dev 26, 64-86.

Gilbert, R., Widom, C.S., Browne, K., Fergusson, D., Webb, E., Janson, S., 2009. Burden and consequences of child maltreatment in high-income countries. Lancet 373, 68-81.

Glynn, L.M., Schetter, C.D., Hobel, C.J., Sandman, C.A., 2008. Pattern of perceived stress and anxiety in pregnancy predicts preterm birth. Health Psychol 27, 43-51.

Goldsmith, H.H., Campos, J.J., 1990. The structure of temperamental fear and pleasure in infants: a psychometric perspective. Child Dev 61, 1944-1964.

Gratz, K.L., Gunderson, J.G., 2006. Preliminary data on an acceptance-based emotion regulation group intervention for deliberate self-harm among women with borderline personality disorder. Behav Ther 37, 25-35.

Green, J.G., McLaughlin, K.A., Berglund, P.A., Gruber, M.J., Sampson, N.A., Zaslavsky, A.M., Kessler, R.C., 2010. Childhood adversities and adult psychiatric disorders in the national comorbidity survey replication I: associations with first onset of DSM-IV disorders. Arch Gen Psychiatry 67, 113-123.

Gulley, L.D., Hankin, B.L., Young, J.F., 2016. Risk for Depression and Anxiety in Youth: The Interaction between Negative Affectivity, Effortful Control, and Stressors. J Abnorm Child Psychol 44, 207-218.

Gunnar, M.R., Hostinar, C.E., Sanchez, M.M., Tottenham, N., Sullivan, R.M., 2015. Parental buffering of fear and stress neurobiology: Reviewing parallels across rodent, monkey, and human models. Soc Neurosci 10, 474-478.

Heim, C., Nemeroff, C.B., 2001. The role of childhood trauma in the neurobiology of mood and anxiety disorders: preclinical and clinical studies. Biol Psychiatry 49, 1023-1039.

Hepburn, L., Eysenck, M.W., 1989. Personality, average mood, and mood variability. Pers Ind Dif 69, 673-685.

Hewitt, P.L., Flett, G.L., Mosher, S.W., 1992. The perceived stress scale: Factor structure and relation to depression symptoms in a psychiatric sample. J Psychopathol Behav Assess 14, 247-257.

Hilmert, C.J., Dominguez, T.P., Schetter, C.D., Srinivas, S.K., Glynn, L.M., Hobel, C.J., Sandman, C.A., 2014. Lifetime racism and blood pressure changes during pregnancy: implications for fetal growth. Health Psychol 33, 43-51.

Huizink, A.C., de Medina, P.G., Mulder, E.J., Visser, G.H., Buitelaar, J.K., 2002. Psychological measures of prenatal stress as predictors of infant temperament. J Am Acad Child Adolesc Psychiatry 41, 1078-1085. 
Ivy, A.S., Brunson, K.L., Sandman, C., Baram, T.Z., 2008. Dysfunctional nurturing behavior in rat dams with limited access to nesting material: a clinically relevant model for early-life stress. Neurosci 154, 1132-1142.

Ivy, A.S., Rex, C.S., Chen, Y., Dube, C., Maras, P.M., Grigoriadis, D.E., Gall, C.M., Lynch, G., Baram, T.Z., 2010. Hippocampal dysfunction and cognitive impairments provoked by chronic early-life stress involve excessive activation of CRH receptors. J Neurosci 30, 13005-13015.

Jahng, S., Wood, P.K., Trull, T.J., 2008. Analysis of affective instability in ecological momentary assessment: Indices using successive difference and group comparison via multilevel modeling. Psychol Methods 13, 354375.

Khashan, A.S., Abel, K.M., McNamee, R., Pedersen, M.G., Webb, R.T., Baker, P.N., Kenny, L.C., Mortensen, P.B., 2008. Higher risk of offspring schizophrenia following antenatal maternal exposure to severe adverse life events. Arch Gen Psychiatry 65, 146-152.

Kiel, E.J., Buss, K.A., 2011. Prospective relations among fearful temperament, protective parenting, and social withdrawal: the role of maternal accuracy in a moderated mediation framework. J Abnorm Child Psychol 39, 953-966.

Kim, H., Seo, J., Namkoong, K., Hwang, E.H., Sohn, S.Y., Kim, S.J., Kang, J.I., 2016. Alexithymia and perfectionism traits are associated with suicidal risk in patients with obsessive-compulsive disorder. J Affect Disord 192, 50-55.

Kingsbury, M., Weeks, M., MacKinnon, N., Evans, J., Mahedy, L., Dykxhoorn, J., Colman, I., 2016. Stressful Life Events During Pregnancy and Offspring Depression: Evidence From a Prospective Cohort Study. J Am Acad Child Adolesc Psychiatry 55, 709-716 e702.

Kovacs, M., 2011. Children's Depression Inventory 2 (CDI 2), 2nd ed. ed. Multi-Health Systems Inc, North Tonawanda, NY.

Koval, P., Ogrinz, B., Kuppens, P., Van den Bergh, O., Tuerlinckx, F., Sutterlin, S., 2013. Affective instability in daily life is predicted by resting heart rate variability. PloS one 8 , e81536.

Kring, A.M., Sloan, D.M., 2010. Emotion Regulation and Psychopathology: A transdiagnostic approach to etiology and treatment. Guildford Press, New York.

Kuppens, P., Van Mechelen, I., Nezlek, J.B., Dossche, D., Timmermans, T., 2007. Individual differences in core affect variability and their relationship to personality and psychological adjustment. Emotion 7, 262-274. Kuppens, P., Verduyn, P., 2015. Looking at emotion regulation through the window of emotion dynamics. Psychol Inq 26, 72-79.

Kuyken, W., Warren, F.C., Taylor, R.S., Whalley, B., Crane, C., Bondolfi, G., Hayes, R., Huijbers, M., Ma, H., Schweizer, S., Segal, Z., Speckens, A., Teasdale, J.D., Van Heeringen, K., Williams, M., Byford, S., Byng, R., Dalgleish, T., 2016. Efficacy of Mindfulness-Based Cognitive Therapy in Prevention of Depressive Relapse: An Individual Patient Data Meta-analysis From Randomized Trials. JAMA Psychiatry.

Larsen, R.J., Diener, E., 1987. Affect intensity as an individual difference characteristic: a review. J Res Pers 21, 139. 
Larsen, R.J., Kasimatis, M., 1990. Individual differences in entrainment of mood to the weekly calendar. Journal of Personality and Social Psychology 58, 164-171.

Lebel, C., Walton, M., Letourneau, N., Giesbrecht, G.F., Kaplan, B.J., Dewey, D., 2015. Prepartum and Postpartum Maternal Depressive Symptoms Are Related to Children's Brain Structure in Preschool. Biol Psychiatry.

Marcus, S.M., Flynn, H.A., Blow, F.C., Barry, K.L., 2003. Depressive symptoms among pregnant women screened in obstetrics settings. J Womens Health (Larchmt) 12, 373-380.

Markon, K.E., Krueger, R.F., Watson, D., 2005. Delineating the structure of normal and abnormal personality: an integrative hierarchical approach. J Pers Soc Psychol 88, 139-157.

Merikangas, K.R., He, J.P., Burstein, M., Swanson, S.A., Avenevoli, S., Cui, L., Benjet, C., Georgiades, K., Swendsen, J., 2010. Lifetime prevalence of mental disorders in U.S. adolescents: results from the National Comorbidity Survey Replication--Adolescent Supplement (NCS-A). J Am Acad Child Adolesc Psychiatry 49, $980-$ 989.

Mischel, W., Shoda, Y., 1995. A cognitive-affective system theory of personality: reconceptualizing situations, dispositions, dynamics, and invariance in personality structure. Psychol Rev 102, 246-268.

Molet, J., Heins, K., Zhuo, X., Mei, Y.T., Regev, L., Baram, T.Z., Stern, H., 2016. Fragmentation and high entropy of neonatal experience predict adolescent emotional outcome. Transl Psychiatry 6, e702.

Monk, C., Spicer, J., Champagne, F.A., 2012. Linking prenatal maternal adversity to developmental outcomes in infants: the role of epigenetic pathways. Dev Psychopathol 24, 1361-1376.

Moullec, G., Maiano, C., Morin, A.J., Monthuy-Blanc, J., Rosello, L., Ninot, G., 2011. A very short visual analog form of the Center for Epidemiologic Studies Depression Scale (CES-D) for the idiographic measurement of depression. J Affect Disord 128, 220-234.

O'Connor, T.G., Heron, J., Golding, J., Glover, V., Team, A.S., 2003. Maternal antenatal anxiety and behavioural/emotional problems in children: a test of a programming hypothesis. J Child Psychol Psychiatry 44, 1025-1036.

O'Donnell, K., O'Connor, T.G., Glover, V., 2009. Prenatal stress and neurodevelopment of the child: focus on the HPA axis and role of the placenta. Dev Neurosci 31, 285-292.

Pearson, R.M., Evans, J., Kounali, D., Lewis, G., Heron, J., Ramchandani, P.G., O'Connor, T.G., Stein, A., 2013. Maternal depression during pregnancy and the postnatal period: risks and possible mechanisms for offspring depression at age 18 years. JAMA psychiatry 70, 1312-1319.

Penner, L.A., Shiffman, S., Paty, J.A., Fritzsche, B.A., 1994. Individual differences in intraperson variability in mood. J Pers Soc Psychol 66, 712-721.

Putnam, S.P., Gartstein, M.A., Rothbart, M.K., 2006. Measurement of fine-grained aspects of toddler temperament: the early childhood behavior questionnaire. Infant Behav Dev 29, 386-401. 
Qiu, A., Anh, T.T., Li, Y., Chen, H., Rifkin-Graboi, A., Broekman, B.F., Kwek, K., Saw, S.M., Chong, Y.S., Gluckman, P.D., Fortier, M.V., Meaney, M.J., 2015. Prenatal maternal depression alters amygdala functional connectivity in 6-month-old infants. Transl Psychiatry 5, e508.

Reinares, M., Sanchez-Moreno, J., Fountoulakis, K.N., 2014. Psychosocial interventions in bipolar disorder: what, for whom, and when. J Affect Disord 156, 46-55.

Richter, P., Werner, J., Heerlein, A., Kraus, A., Sauer, H., 1998. On the validity of the Beck Depression Inventory. A review. Psychopathol 31, 160-168.

Rini, C.K., Dunkel-Schetter, C., Wadhwa, P.D., Sandman, C.A., 1999. Psychological adaptation and birth outcomes: the role of personal resources, stress, and sociocultural context in pregnancy. Health Psychol 18, 333345.

Rothbart, M.K., Ahadi, S.A., Hershey, K.L., Fisher, P., 2001. Investigations of temperament at three to seven years: the Children's Behavior Questionnaire. Child Dev 72, 1394-1408.

Rouleau, C.R., Tomfohr-Madsen, L.M., Campbell, T.S., Letourneau, N., O'Beirne, M., Giesbrecht, G.F., Team, A.P.S., 2016. The role of maternal cardiac vagal control in the association between depressive symptoms and gestational hypertension. Biological Psychol 117, 32-42.

Sandman, C.A., Class, Q.A., Glynn, L.M., Davis, E.P., 2015. Neurobehavioral disorders and developmental origins of health and disease, In: Rosenfeld, C.S. (Ed.), The Epigenome and Developmental Origins of Health and Disease, pp. 235-266.

Santor, D.A., Coyne, J.A., 1997. Shortening the CES-D to improve its ability to detect cases of depression. Psychological Assess 9, 233-243.

Sarason, S.B., Davison, K.S., Lighthall, F.F., Waite, R.R., Ruebush, B.K., 1960. Anxiety in Elementary School Children. Wiley, New York.

Sayal, K., Heron, J., Maughan, B., Rowe, R., Ramchandani, P., 2014. Infant temperament and childhood psychiatric disorder: longitudinal study. Child Care Health Dev 40, 292-297.

Seligman, L.D., Ollendick, T.H., Langley, A.K., Baldacci, H.B., 2004. The utility of measures of child and adolescent anxiety: a meta-analytic review of the Revised Children's Manifest Anxiety Scale, the State-Trait Anxiety Inventory for Children, and the Child Behavior Checklist. J Clin Child Adolesc Psychol 53 33, 557-565.

Shea, A.K., Kamath, M.V., Fleming, A., Streiner, D.L., Redmond, K., Steiner, M., 2008. The effect of depression on heart rate variability during pregnancy. A naturalistic study. Clin Auton Res 18, 203-212.

Slopen, N., McLaughlin, K.A., Fox, N.A., Zeanah, C.H., Nelson, C.A., 2012. Alterations in neural processing and psychopathology in children raised in institutions. Arch Gen Psychiatry 69, 1022-1030.

Solhan, M.B., Trull, T.J., Jahng, S., Wood, P.K., 2009. Clinical assessment of affective instability: comparing EMA indices, questionnaire reports, and retrospective recall. Psychol Assess 21, 425-436. 
Spielberger, C.D., 1979. State-Trait Personality Inventory (STPI) preliminary test manual. University of South Florida.

Spielberger, C.D., Edwards, C.D., Montouri, J., Lushene, R., 1973. The State-Trait Anxiety Inventory for Children. Consulting Psychologist Press, Palo Alto.

Spijkerman, M.P., Pots, W.T., Bohlmeijer, E.T., 2016. Effectiveness of online mindfulness-based interventions in improving mental health: A review and meta-analysis of randomised controlled trials. Clin Psychol Rev 45, 102114.

Spinelli, S., Chefer, S., Suomi, S.J., Higley, J.D., Barr, C.S., Stein, E., 2009. Early-life stress induces long-term morphologic changes in primate brain. Arch Gen Psychiatry 66, 658-665.

Stockings, E., Degenhardt, L., Lee, Y.Y., Mihalopoulos, C., Liu, A., Hobbs, M., Patton, G., 2015. Symptom screening scales for detecting major depressive disorder in children and adolescents: a systematic review and metaanalysis of reliability, validity and diagnostic utility. J Affect Disord 174, 447-463.

Stone, A.A., Shiffman, S., 1994. Ecological momentary assessment (EMA) in behavioral medicine. Ann Behav Med 16, 199-202.

Thayer, J.F., Ahs, F., Fredrikson, M., Sollers, J.J., 3rd, Wager, T.D., 2012. A meta-analysis of heart rate variability and neuroimaging studies: implications for heart rate variability as a marker of stress and health. Neurosci Biobehav Rev 36, 747-756.

Thompson, R.J., Berenbaum, H., Bredemeier, K., 2011. Cross-sectional and longitudinal relations between affective instability and depression. J Affect Disord 130, 53-59.

Timbremont, B., Braet, C., Dreessen, L., 2004. Assessing depression in youth: relation between the Children's Depression Inventory and a structured interview. J Clin Child Adolesc Psychol 33, 149-157.

Tortella-Feliu, M., Balle, M., Sese, A., 2010. Relationships between negative affectivity, emotion regulation, anxiety, and depressive symptoms in adolescents as examined through structural equation modeling. J Anxiety Disord 24, 686-693.

Van Leeuwen, P., Geue, D., Thiel, M., Cysarz, D., Lange, S., Romano, M.C., Wessel, N., Kurths, J., Gronemeyer, D.H., 2009. Influence of paced maternal breathing on fetal-maternal heart rate coordination. Proc Nat Acad Sci 106, 13661-13666.

Wessman, A.E., Ricks, D.F., 1966. Mood and Personality. Holt, Rinehart \& Winston, New York.

Woon, F.L., Hedges, D.W., 2008. Hippocampal and amygdala volumes in children and adults with childhood maltreatment-related posttraumatic stress disorder: a meta-analysis. Hippocampus 18, 729-736.

Worobey, J., Blajda, J.M., 1989. Temperament ratings at 1 week, 1 month and 1 year: differential stability of activity and emotionality. Dev Psychol 25, 257-263. 


\section{Figures:}

Figure 1. Description of study protocol for Cohorts 1 and 2.

Prenatal

Weeks' Gestation

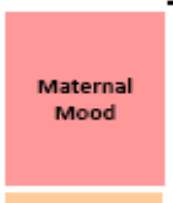

Child Risk for Internalizing Disorders

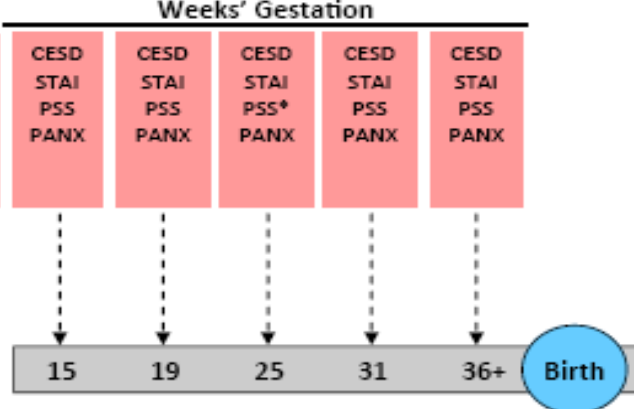

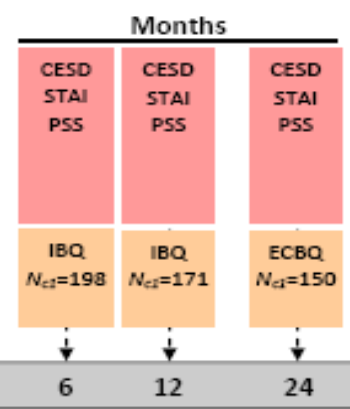

Postnatal

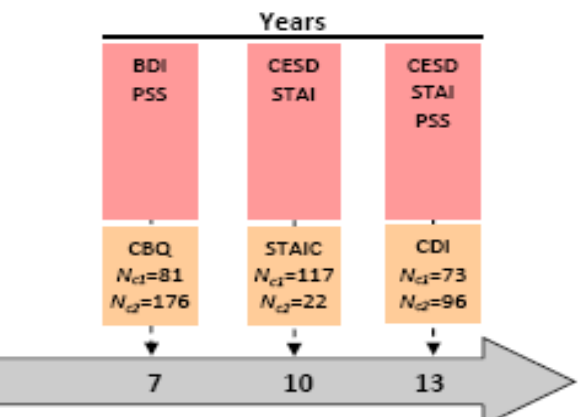

Note: The different numbers of children assessed at each age were determined by the number of children in these longitudinal cohorts who had aged into the assessment window during the $\mathrm{NIH}$-grant periods that funded this work. CESD = Center for Epidemiologic Studies Depression Scale; STAI = State-Trait Personality Inventory: PSS = Perceived Stress Scale; PANX = Pregnancy Specific Anxiety Scale; BDI = Beck Depression Inventory: IBQ = Infant Behavior Questionnaire; $\mathrm{ECBQ}=$ Early Childhood Behavior Questionnaire; $\mathrm{CBQ}=\mathrm{Children's} \mathrm{Behavior}$ Questionnaire; STAIC = State-Trait Anxiety Inventory for Children; CDI = Children's Depression Inventory: "PSS not administered at 25 weeks' gestation in Cohort 2

Figure 2. Bivariate correlations between maternal prenatal mood entropy and maternal report of child negative affectivity through 7 years of age $(* * p<.01)$.

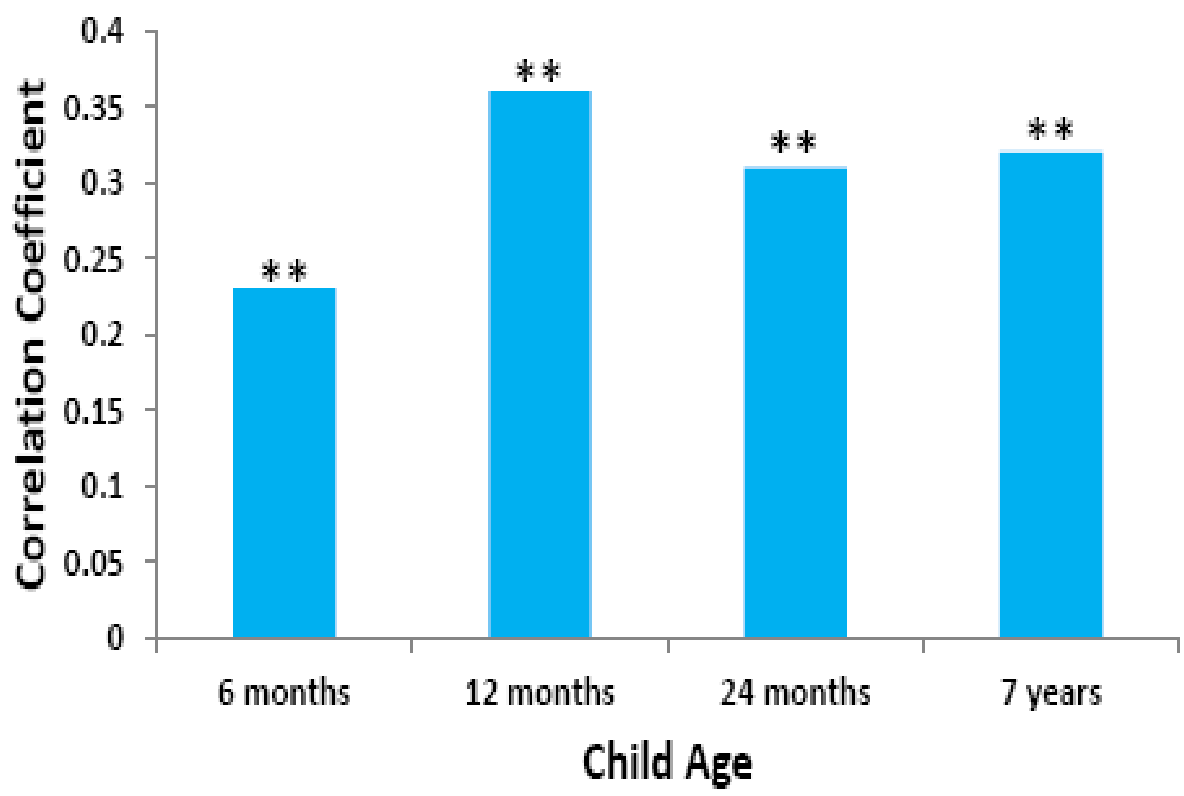


Figure 3. Correlation between maternal prenatal mood entropy and child self-report of anxiety and adolescent self-report of depressive symptoms.
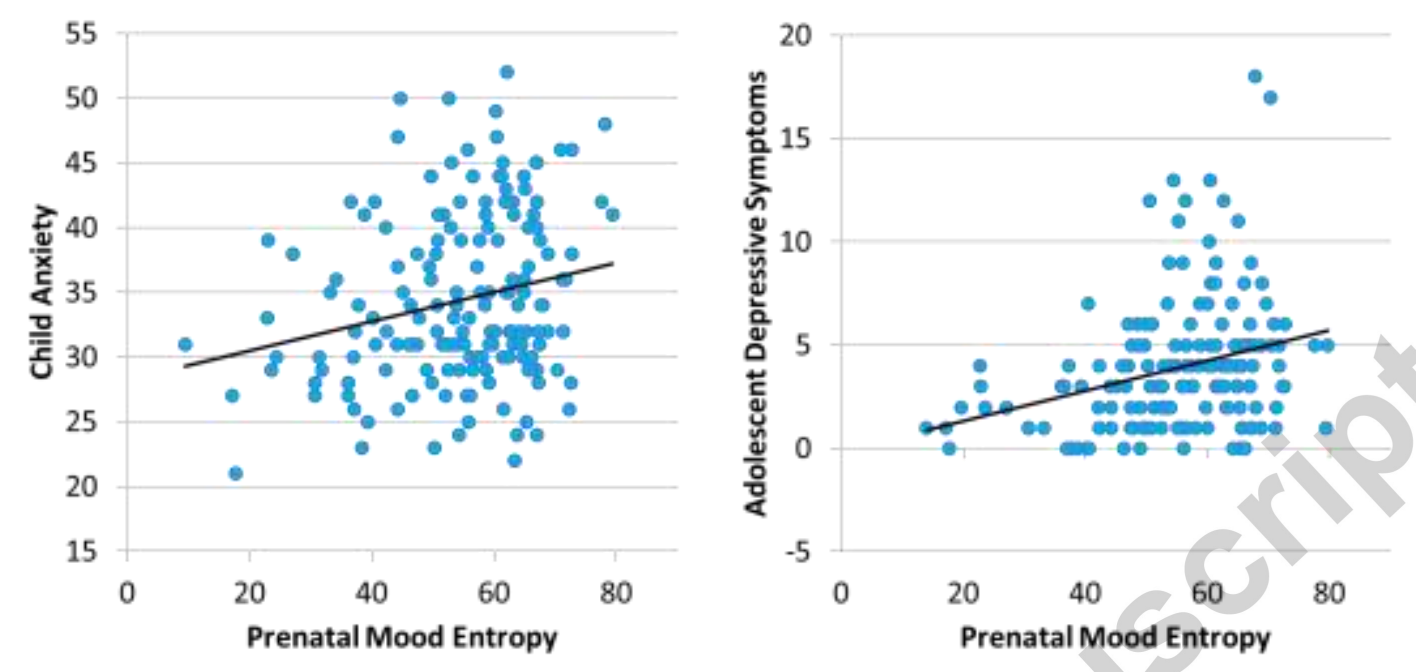

Tables:

Table 1. Participant Characteristics for Cohorts 1 and 2.

\begin{tabular}{|c|c|c|}
\hline 8 & $\begin{array}{l}\text { Cohort } 1 \\
(N=227)\end{array}$ & $\begin{array}{l}\text { Cohort } 2 \\
(N=180)\end{array}$ \\
\hline \multicolumn{3}{|l|}{ Maternal Race/Ethnicity (\%) } \\
\hline Latina & 27.3 & 22.0 \\
\hline Black & 2.6 & 10.7 \\
\hline Asian & 9.7 & 11.9 \\
\hline Non-Hispanic White & 48.5 & 50.3 \\
\hline Other & 11.9 & 5.1 \\
\hline Maternal Age (mean years) & 30.0 & 30.8 \\
\hline \multicolumn{3}{|l|}{ Education (\%) } \\
\hline High School or Less & 14.5 & 17.0 \\
\hline Some College, Associates or Vocational & 40.5 & 32.2 \\
\hline \multicolumn{3}{|l|}{ Degree } \\
\hline 4-year College Degree & 28.6 & 31.1 \\
\hline
\end{tabular}


Graduate Degree

Annual Household Income (mean; US \$)

Cohabitation with Child's Father (\% yes)

Birth Order (\% first born)

Child Sex (\% female)

Length of Gestation (mean weeks)

Mood Entropy (mean)
16.3

60,784

89.4

43.6

48.5

39.2

53.1
53.3

39.0

19.8

66,129

88.0

58.7

57.8 
Table 2. Example of Computation of Entropy for STAI (10 items on a 4-point scale)

\begin{tabular}{lcc}
\hline Item & Response & $\begin{array}{c}\text { Coded } \\
\text { Response }\end{array}$ \\
\hline Calm & 1 & 4 \\
Presently Worrying & 2 & 2 \\
Nervous & 2 & 2 \\
Relaxed & 1 & 4 \\
Worried & 2 & 2 \\
Steady & 1 & 4 \\
Frightened & 1 & 1 \\
Tense & 3 & 3 \\
At Ease & 1 & 4 \\
Jittery & 2 & 2 \\
\hline
\end{tabular}

\begin{tabular}{lccc}
\hline Response & Frequency & $\mathbf{p}_{\mathbf{e}}$ & $\mathbf{p}_{\mathbf{e}} \log _{\mathbf{2}} \mathbf{p}_{\mathbf{e}}$ \\
\hline $\mathbf{1}$ & 1 & 0.10 & -0.33 \\
$\mathbf{2}$ & 4 & 0.40 & -0.53 \\
$\mathbf{3}$ & 1 & 0.10 & -0.33 \\
$\mathbf{4}$ & 4 & 0.40 & -0.53 \\
Sum & 10 & 1.00 & -1.72 \\
Normalized Entropy & & & $(1.72 / 2.00)^{*} 100=86$ \\
\hline
\end{tabular}


Table 3. Summary of regression analyses assessing the contributions of pre and postnatal mood entropy to child outcomes.

\begin{tabular}{|c|c|c|c|c|c|c|c|c|c|}
\hline & \multicolumn{6}{|c|}{ Maternal Report of Negative Affectivity } & \multicolumn{3}{|c|}{$\begin{array}{l}\text { Child Report of Anxiety } \\
\text { and Depressive Symptoms }\end{array}$} \\
\hline & \multicolumn{2}{|c|}{ 12-mos } & \multicolumn{2}{|c|}{ 24-mos } & \multicolumn{2}{|c|}{ 7-Years } & 10-years & \multicolumn{2}{|c|}{ 13-years } \\
\hline & $\beta$ & $p$-value & $\beta$ & $p$-value & $\beta$ & $\mathrm{p}$-value & p-value & $\beta$ & $p$-value \\
\hline Prenatal Mood Entropy & .25 & .00 & .21 & .02 & .23 & .00 & .17 & .24 & .00 \\
\hline Postnatal Mood Entropy & .20 & .02 & .24 & .01 & .22 & .00 & .07 & .15 & .05 \\
\hline
\end{tabular}

Highlights

- Examines prenatal mood unpredictability as a risk factor for child temperament and internalizing symptoms

- Prenatal mood entropy predicts maternal report of child negative affect through 7 years

- Prenatal mood entropy predicts child report of anxiety and 10 and depressive symptoms at 13 years

- Patterns of maternal mood, in addition to level or valence, may influence child development 